\title{
The Development of Media and Special Event to Support Knowledge of Arts and Culture Entitled "Dancing with Single-Head Drum Accompaniment" for Young People through Social Service Learning and Community-Based Learning
}

\author{
Kuntida Thamwipat ${ }^{1} \&$ Pornpapatsorn Princhankol $^{1}$ \\ ${ }^{1}$ Faculty of Industrial Education and Technology, King Mongkut's University of Technology Thonburi, \\ Bangkok, Thailand \\ Correspondence: Kuntida Thamwipat, Faculty of Industrial Education and Technology, King Mongkut's \\ University of Technology Thonburi, Bangkok, Thailand. E-mail: kuntida.tha@kmutt.ac.th
}

Received: June 26, 2018

Accepted: September 3, $2018 \quad$ Online Published: November 27, 2018

doi:10.5539/ies.v11n12p133

URL: https://doi.org/10.5539/ies.v11n12p133

\begin{abstract}
This research and development was aimed (a) to develop media and special event to support knowledge of arts and culture entitled "Dancing with Single-Head Drum Accompaniment" for young people through social service learning and community-based learning, (b) to evaluate the quality of such media and special event, (c) to measure the learning achievements and the satisfaction of young people towards such media and special event, and (d) to measure the learning achievements and the satisfaction of students towards social service learning and community-based learning. The sampling group in this study consisted of 30 young people in the community under the bridge Zone 1 at Pracha-utit 76 who were chosen using purposive sampling method out of those who were willing to participate in the activities on the $11^{\text {th }}$ of November, 2017 and 16 graduate students from Faculty of Industrial Education and Technology, King Mongkut's University of Technology Thonburi who enrolled in the LTM 652 course. The statistical analysis included mean score, standard deviation and dependent t-test. The results showed that the quality of the contents was at a very good level $(\overline{\mathrm{x}}=4.70$, S.D. $=0.50)$ and the quality of the media and special event was at a very good level $(\bar{x}=4.80$, S.D. $=0.40)$. The learning achievements of young people showed that their average post-test score for dancing with single-head drum accompaniment was higher than the average pre-test score with a statistically significant difference at the.01 level. The satisfaction of young people was at a high level $(\overline{\mathrm{x}}=4.40$, S.D. $=0.60)$. The learning achievements of graduate students showed that their average post-test score for social service learning and community-based learning was higher than the average pre-test score with a statistically significance difference at the. 01 level. The satisfaction of the graduate students was at a high level $(\overline{\mathrm{x}}=4.10$, S.D. $=1.60)$. Therefore, the developed media and special event through social service learning and community-based learning can be used in the future.
\end{abstract}

Keywords: media and special event, knowledge of arts and culture, social service learning, community-based learning

\section{Introduction}

National development to keep up with the changes in the world and the newer technology results in changes in the way of life and society. Adopting other cultures without thinking causes many people to ignore and forget national culture which is unique to the country. There are many elements of culture which need to be protected and preserved for future generations. According to the Office of the National Culture Commission, the development of Thailand in the past years according to the National Economic and Social Development Plan focused on economic issues, resulting in advancements in economic status. However, there were many social and cultural issues although the Office of the National Culture Commission has announced plans and policies to establish Thai culture for both governmental and private sectors (Office of the National Culture Commission, 2001). In addition, the world without border or the world-wide web is one of the major factors in changing the Thai society so that there are many kinds of information for access but this information is consumed without selection and thinking, resulting in the fact that young people receive everything without real knowledge and that they ignore Thai roots and foundation. Therefore, it is likely that local wisdom and Thai culture will be discarded 
and there will be no cultural harmony in Thailand and Thai people will no longer understand Thai values. In the end, this is a critical cultural issue (Thanasa-nguanwong, 2013).

Corporations prided themselves on their "social responsibility". Their premise was that with the great opportunities they were afforded, companies needed to "give back" to society through participation in and contributions to not-for-profit organization committed to confront society's most pressing problems from poverty to education to cultural and health enrichment. Typical community relations objectives may include gaining the favorable opinion of the community, to establish a personal relationship between management and community leaders (Seitel, 2017).

There are many communities under the bridges in many parts of Bangkok where many homeless people stay. Bangkok Metropolitan Authority and National Housing Authority collaborated to find shelters to over 700 families. There are now 3 zones for them and these zones are not far from their previous establishments. Zone 1 is the community under the bridge at Pracha-utit 76 in Toong-kru district. Zone 2 is the community under the bridge in Sai-mai area and Zone 3 is the community under the bridge at Onnuch 14 in Prawet district. The target group in this research is Zone 1 at Pracha-utit 76 in Toong-kru district, Bangkok, which is around 10 kilometers away from the main campus. There are about 200 families. There is a communal area for playground and recreation as well as pre-school learning center which also serves as their meeting point and activity area. Around $70 \%$ of the population work as itinerant junk dealers and therefore they are quite poor. Their education level is not high and there are problems among young people such as loitering and drug (Leewangsee, 2016).

Graduate students who enrolled in the LTM 652 Principles and Theories of Mass Communications course were aware of their role and the importance of media as well as the attitudes and the behaviors of the viewers, especially among young people in such communities. Because this course integrated social service learning and community-based learning, the graduate students were willing to apply their knowledge in real situations. The community under the bridge Zone 1 at Pracha-utit 76 was suitable for such course. The researchers consulted the findings from social service learning (Nuangchalerm, 2015) which showed that social service learning helps learners to apply their classroom knowledge on their field study. After the field trip, it was found that their learning becomes meaningful and valuable. Regarding community-based learning, Chanchamsai (2015) says that community-based learning helps learners to work in sub-groups to learn among themselves. Learners change in many ways. For instance, their learning achievements increase. They communicate better. They have better social skills and they collaborate with others for the benefits of the community. Their disagreements decrease and they help as well as support others. They have confidence in themselves and gain better mental health. These are the benefits of community-based learning.

In this research, there were enough young people in the community under the bridge Zone 1 at Pracha-utit 76. Before we began, we talked to local people and let graduate students run their own project and develop media and special events entitled "Dancing with Single-Head Drum Accompaniment" for young people based on social service learning and community-based learning which they studied in the LTM 652 Principles and Theories of Mass Communications course. It was considered to be an active learning approach for graduate students who pursue a degree in Learning Technology and Mass Communications.

\subsection{Objectives}

The objectives of this research were as follows:

1) To develop media and special event to support knowledge of arts and culture entitled "Dancing with Single-Head Drum Accompaniment" for young people through social service learning and community-based learning

2) To evaluate the quality of the media and special event to support knowledge of arts and culture entitled "Dancing with Single-Head Drum Accompaniment" for young people through social service learning and community-based learning

3) To measure the learning achievements and the satisfaction of young people towards the media and special event to support knowledge of arts and culture entitled "Dancing with Single-Head Drum Accompaniment"

4) To measure the learning achievements and the satisfaction of students towards social service learning and community-based learning.

\subsection{Research Hypotheses}

The hypotheses of this research were as follows:

1) The quality of the media and special event to support knowledge of arts and culture entitled "Dancing with 
Single-Head Drum Accompaniment" for young people would be at a good level.

2) The learning achievements of young people towards the media and special event to support knowledge of arts and culture entitled "Dancing with Single-Head Drum Accompaniment" would show that their average post-test score was higher with a statistically significant difference at the.01 level. The satisfaction towards the media and special event would be at a high level.

3) The learning achievements of students towards social service learning and community-based learning would show that their average post-test score was higher with a statistically significant difference at the.01 level. The satisfaction towards the learning approach would be at a high level.

\subsection{Expected Outcomes}

The expected outcomes of this research were as follows:

1) The young people would gain knowledge and satisfaction from the media and special event to support knowledge of arts and culture entitled "Dancing with Single-Head Drum Accompaniment".

2) This research would be used as a basis for active learning for graduate students who pursue a degree in Learning Technology and Mass Communications.

3) The graduate students from the Faculty of Industrial Education and Technology would gain experience from social service learning and community-based learning and they could apply their classroom knowledge in real communities.

\section{Research Scope}

\subsection{Population}

The population in this research consisted of 2 groups as follows:

1) Around 100 young people in the community under the bridge zone 1

2) Around 120 graduate students in the Faculty of Industrial Education and Technology, King Mongkut's University of Technology Thonburi in the first semester of the academic year 2017.

\subsection{Sampling Group}

There were 2 sampling groups in this study as follows:

1) There were 30 young people in the community under the bridge zone 1 at Pracha-utit 76 who were chosen using purposive sampling method out of those who were willing to participate in the event on the $11^{\text {th }}$ of November 2017 (Babbie, 1995).

2) There were 16 graduate students who enrolled in the LTM 652 course in the first semester of the academic year 2017. They were chosen using purposive sampling method out of those who were willing to develop media and special event to support knowledge of arts and culture through social service learning and community-based learning (Babbie, 1995).

\subsection{Expert Panels}

The experts were those with knowledge and expertise in assessing the quality of the media and special event to support knowledge of arts and culture entitled "Dancing with Single-Head Drum Accompaniment" for young people in the community under the bridge. The experts were chosen using purposive sampling method out of those who were experts in this field and were willing to evaluate the quality of the media and activities. There were 3 experts in contents and there were 3 experts in media and activities and there were 3 experts in measurements and evaluation to measure the IOC value of the questionnaire and the tests.

\section{Research Tools}

The research tools in this study were as follows:

1) Media and special event to support knowledge of arts and culture entitled "Dancing with Single-Head Drum Accompaniment" for young people through social service learning and community-based learning

2) The questionnaires to evaluate the quality of contents and the quality of media and special event with Likert's 5-rating scale varying from the highest, high, moderate, low and the lowest (Srisa-ard, 2010).

3) The learning achievement test and the satisfaction questionnaire for young people in the community under the bridge. The test contained 20 multiple-choice items.

4) The learning achievement test and the satisfaction questionnaire for graduate students regarding the social 
service learning and community-based learning with Likert's 5-rating scale varying from the highest, high, moderate, low and the lowest (Srisa-ard, 2010).

\section{Data Analysis}

The data were analyzed using the following statistical methods: mean score, standard deviation and dependent t-test.

\section{Research Results}

\subsection{The Results from the Development of Media and Special Event to Support Knowledge of Arts and Culture}

The media and special event to support knowledge of arts and culture entitled "Dancing with Single-Head Drum Accompaniment" for young people through social service learning and community-based learning were developed according to the following steps as shown in Table 1; Plan Do Check Act from Shewhart Cycle which is a control and continual improvement method made famous by Deming (1986).

Table 1. Steps in the development of media and special event (Plan-Do-Check-Act)

\begin{tabular}{ll}
\hline Step & Description \\
& The researchers designed social service learning and community-based learning in the LTM 652 course \\
so that the graduate students could use their knowledge on their field trip. The students needed to learn \\
how to write their research proposal and the budget plan to ask for funding to support cultural activities \\
from the Faculty of Industrial Education and Technology. The students planned their activities and \\
talked to local people until they had the topic which met the demands of the local people. The activities \\
were done according to the willingness and the skills of the students. \\
The students developed the media and special event to support knowledge of arts and culture entitled \\
"Dancing with Single-Head Drum Accompaniment" for young people through social service learning \\
and community-based learning according to ADDIE Model (Santajit, 2013) which consists of \\
Analysis, Design, Development, Implementation and Evaluation. Each stage was supervised by the \\
experts to check the quality of the contents and the quality of the media and activities as well as the \\
quality of the measurements and evaluation. The field trip was held on the 11 ${ }^{\text {th }}$ of November 2017 at \\
the community under the bridge zone 1 at Pracha-utit 76 . The media and special event was presented to \\
Do young people and 80 other people in the community. \\
Every week the researchers and the students reported their progress in their classroom and the social \\
media network, or Facebook, with the group LTM 652/2560 so that everybody was aware of the issues \\
and could help resolve any issues. \\
The students worked in their team to collaborate and participate in their work before and after the \\
special event. Because most students worked and studied part-time during their weekend classes, they \\
did not have much time to participate. However, the researchers persuaded them to understand that \\
these activities could be used as a way to develop their own thesis in the future through After Action \\
Review (AAR).
\end{tabular}

The special event held on the $11^{\text {th }}$ of November 2017 at the community under the bridge was shown in Figure 1 below. 

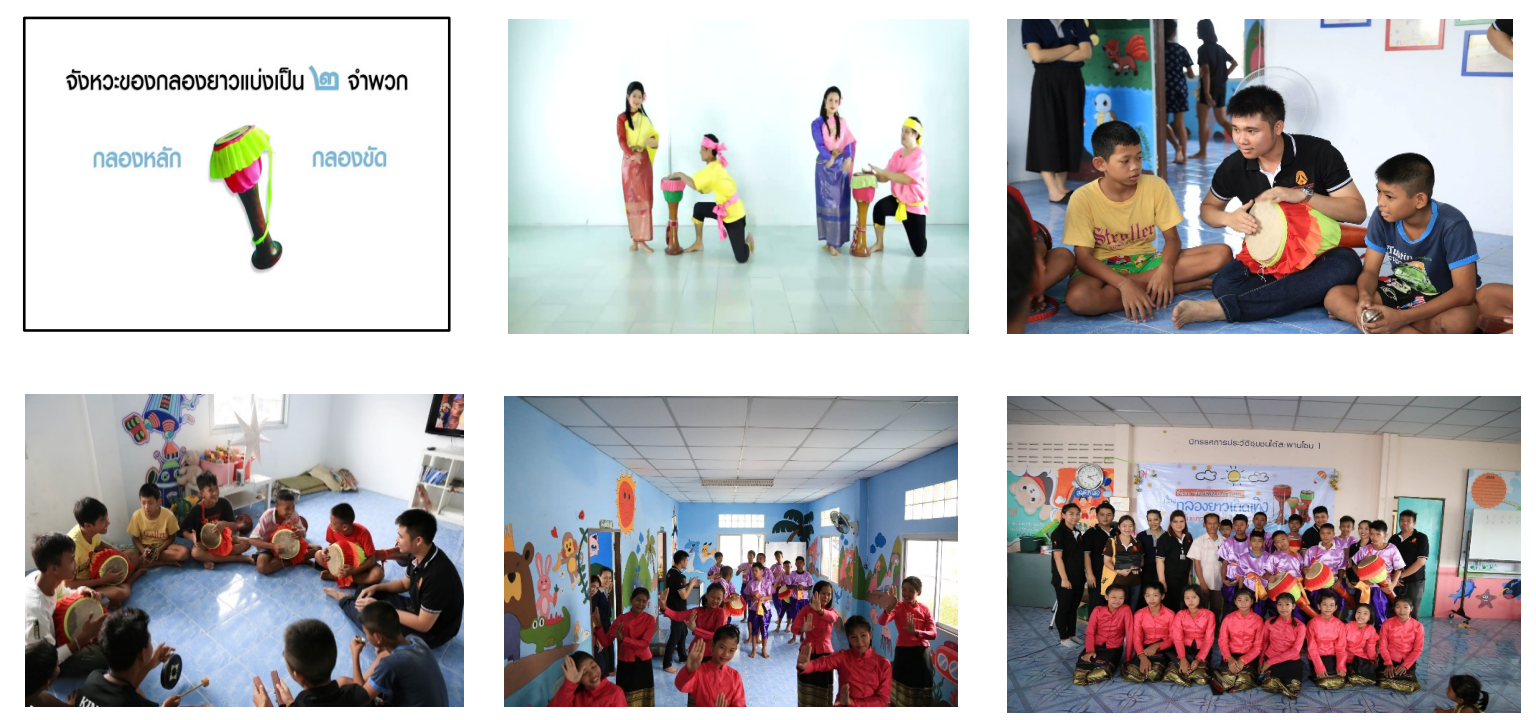

Figure 1. Screenshot of the media and photos of activities

\subsection{The Quality of the Media and Special Event to Support Knowledge of Arts and Culture}

The media and special event to support knowledge of arts and culture entitled "Dancing with Single-Head Drum Accompaniment" for young people through social service learning and community-based learning were evaluated by the experts and shown in the table below.

Table 2. Quality of the media and special event as evaluated by the experts

\begin{tabular}{lccc}
\hline Item & Mean & S.D. & Meaning \\
\hline Quality of contents evaluated by the experts in contents & 4.70 & 0.50 & Very Good \\
Quality of media and activities by the experts in media and activities & 4.80 & 0.40 & Very Good \\
\hline
\end{tabular}

The results from the quality evaluation by the experts showed that the quality of the media was at a very good level $(\overline{\mathrm{x}}=4.70, \mathrm{~S} . \mathrm{D} .=0.50)$ and the quality of the media and special event was at a very good level $(\overline{\mathrm{x}}=4.80$, S.D. $=0.40)$. The results confirmed the research hypothesis.

\subsection{The Learning Achievements and Satisfaction of Young People towards the Media and Special Event to Support Knowledge of Arts and Culture}

The learning achievements of young people showed that their average post-test score was higher than their average pre-test score with a statistically significant difference at the.01 level. The satisfaction of young people towards the media and special event was at a high level $(\overline{\mathrm{x}}=4.40$, S.D. $=0.60)$. The results confirmed the research hypothesis.

\subsection{The Learning Achievements and Satisfaction of Graduate Students towards the Social Service Learning and Community-Based Learning}

The learning achievements of graduate students showed that their average post-test score was higher than their average pre-test score with a statistically significant difference at the. 01 level. The satisfaction of graduate students towards the social service learning and special event was at a high level $(\overline{\mathrm{x}}=4.10$, S.D. $=1.60)$. The results confirmed the research hypothesis.

\section{Research Discussion}

The research study into the development of media and special event to support knowledge of arts and culture entitled "Dancing with Single-Head Drum Accompaniment" for young people through social learning service and community-based learning followed the social learning service concept by Nuangchalerm (2015) and community-based learning concept by Chanchamsai (2015). Moreover, it followed the ADDIE Model (Morrison, 2010) which consists of Analysis, Design, Development, Implementation and Evaluation. Each stage of the research was supervised by the experts so that they could evaluate the quality of the contents, the media and special and the measurements as well as the evaluation. Moreover it met the University community relations 
objectives; to gain the favorable opinion of the community (Seitel, 2017).

The quality of the contents was at a very good level $(\overline{\mathrm{x}}=4.70$, S.D. $=0.50)$ and the quality of the media and special event was at a very good level $(\overline{\mathrm{x}}=4.80$, S.D. $=0.40)$. The results confirmed the research hypothesis and were similar to the research into the development of digital multimedia and special events for the funding of poor students on the occasion of the $50^{\text {th }}$ anniversary for Faculty of Industrial Education and Technology, King Mongkut's University of Technology Thonburi (Princhankol, Thamwipat, \& Duangrit, 2017) in that the quality of the contents was at a very good level $(\overline{\mathrm{x}}=4.86$, S.D. $=0.23)$ and the quality of the media and activities was at a very good level $(\overline{\mathrm{x}}=4.69$, S.D. $=0.44)$.

The learning achievements of young people showed that their average post-test score for their media and special event entitled "Dancing with Single-Head Drum Accompaniment" was higher than the average pre-test score with a statistically significant difference at the.01 level. The satisfaction of young people was at a high level $(\overline{\mathrm{x}}=4.40, \mathrm{~S} . \mathrm{D} .=0.60)$. The results confirmed the research hypothesis. The learning achievements of graduate students showed that their average post-test score for social service learning and community-based learning was higher than their average pre-test score with a statistically significant difference at the.01 level. The satisfaction of graduate students towards the social service learning and special event was at a high level $(\overline{\mathrm{x}}=4.10$, S.D.=1.60). The results confirmed the research hypothesis. These results were similar to the results in the research by Rattanamuk (2013) who conducted a study into social service learning and the building of citizenship for social welfare in that the teachers with an active learning approach and social problems for their learners to think and do projects will help their learners to increase their learning achievements as well as their satisfaction so that they could improve their thinking skills and behaviors.

\section{Suggestions}

\subsection{Suggestions from the Research Results}

1) The instructors who adopt an active learning approach such as social service learning and community-based learning should work in a team so that they can become coaches and mentors to their students when the students need to apply their knowledge in the community. However, the community for social service learning should not be too far from the campus because it will not be convenient for the journey and the collaboration with the local people.

2) The IT technology should be used, for instance, social media network or Facebook, so that the instructors could communicate with their students. A closed group is a good option for graduate students who participate in a special course (or weekend courses) because most of them have to work full-time and study part-time on the weekend and therefore they do not have much time to meet the instructors.

3) The instructors should do After Action Review (AAR) in order to show their students how each issue could be resolved and they might have better options for the development of media and special event as well as their thesis project after the field trip. The data would be fresh and there might be reflections in the closed Facebook group.

\subsection{Suggestion for Further Research}

There should be a development of media entitled "Dancing with Single-Head Drum Accompaniment" as a series of video clips on YouTube so that young people can learn from this media at any time.

\section{Acknowledgments}

The researchers would like to acknowledge the funding for cultural activities from Faculty of Industrial Education and Technology, King Mongkut's University of Technology Thonburi.

\section{References}

Babbie, E. (1995). The Practice of Social Research (7th ed.). Wadsworth Publishing Company.

Chanchamsai, M. (2015). A Case Study of Community-Based Learning with Architectural Design and Housing Development of Low-Income Families (Ban Man-kong Community Rama IX Bo 3). Rajabhat Phra Nakorn Academic Journal, 10(1), 148.
Deming
$\mathrm{W}$.
(1986).
Shewhart
Cycle.
Retrieved
from

Leewangsee, C. (2016). Interview. [10 September 2016].

Morrison, G. R. (2010). Designing Effective Instruction (6th ed.). John Wiley \& Sons. 
Nuangchalerm, P. (2015). Social Service Learning. Rajabhat Kalasin Academic Journal, 2(1), 9-18.

Office of the National Culture Commission. (2001). OPAC WEB. Retrieved from http://library.christian.ac.th/opac/showsearch_bk.php?pointer=T006162

Princhankol, P., Thamwipat, K., \& Duangrit, P. (2017). The Development of Digital Multimedia and Special Events for the Funding of Poor Students on the Occasion of 50th Anniversary for Faculty of Industrial Education and Technology, King Mongkut's University of Technology Thonburi. 3rd International Conference on Education and Distance Learning 2017. Galle Face Hotel, Colombo, Srilanka.

Rattanamuk, S. (2013). Social service learning and the building of citizenship for social welfare (Master's thesis, Thammasat University).

Seitel, P. (2017). The Practice of Public Relation (13th ed.). Pearson Educaiton Limited.

Srisa-ard, B. (2010). Basic Research. Bangkok: Suweeriyasarn Publishing.

Thanasa-nguanwong, J. (2013). Life and Culture in Thailand. Retrieved from http://e-learning.e-tech.ac.th/learninghtml/s1301/unit03.html\#a00

\section{Copyrights}

Copyright for this article is retained by the author(s), with first publication rights granted to the journal.

This is an open-access article distributed under the terms and conditions of the Creative Commons Attribution license (http://creativecommons.org/licenses/by/4.0/). 